"new views," nor limied myself to matters which came within the range of the "new science." The criterion of merit struck me as highly remarkable and certainly very new, and indicative of a degree of toleration which, if not altogether new, is at least unusual amongst men of science. The passage quoted by Mr. Cunningham demonstrates that I expressed myself very badly. Soon, however, I shall have an opportunity of trying to do better, and I suggest that until then Mr. Cunningham shall suspend judgment.

In previous communications to NATURE I have admitted that Mendelism may conceivably shed a light on the function of sex, but I challenged its exponents to mention a single other problem on which it has the remotest bearing. No one has as yet mentioned another problem, and Mr. Cunningham denies, apparently, that it has a bearing on that of sex. Must we assume, then, that it sheds no light on anything at all?

IF, instead of dwelling on the dangers incurred by those who venture to differ from Darwin, Mr. Lock (November 14) demonstrated my errors, he would be more convincing; and, since he is probably the only human being who doubts the blending of the black and white races in Mulattoes and their descendants, it would be well if he, rather than I, undertook the collection of pedigrees. He would feel himself on the track of a great discovery which would enlighten even Mulattoes, whereas I should feel I was wasting time. I do not know what I can gain from the renewed study which he is good enough to suggest. I am well aware of the three principal Mendelian doctrines-segregation of units, independent inheritance of characters, Mendel's law is the greatest of biological discoveries-and the more I see and read the more thoroughly I am convinced that they are all demonstrably erroneous, and that nothing but the restricted area covered by Mendelian studies has prevented a recognition of that fact by Mendelians themselves.

According to selectionists blending is the function, or at least the effect of conjugation. According to Mendelians, not blending, but segregation, occurs. Taken by itself, this doctrine assigns no function to conjugation; it merely controverts the theory of blending. Taken in conjunction with the Mendelian hypothesis of the independent inheritance of characters, it assigns to conjugation the function of effecting an exchange of units between the paternal and maternal sets of allelomorphs. That much the Mendelian doctrines imply - that much and no more. Clearly, then, Mendelism is concerned solely with the function of sex. At any rate, I can conceive of nothing else, and, judoing from their spoken and written communications, Mendelians have been so rapt in contemplation of the grandeur of the discovery that they have given no further thought to the matter.

$$
\text { " But everybody said," quoth he, }
$$

"That 'twas a famous victory.",

$\mathrm{Mr}$. Lock declares that, since conjugation is nearly universal, all, or nearly all, the questions of heredity are problems of the function of sex. He might as reasonably argue that, since assimilation and death are universal, all problems of heredity are problems of assimilation and death. The looseness of thought which pervades Mendelism is well illustrated by his remarks on parthenogenesis and bud-variation. Mendelian segregation implies the separation of allelomorphs which, through the union of two gametes, have previously met in a zygote. There can be no meeting, and therefore no separation when reproduction is parthenogenetic. Mr. Lock, in fact, enunciates the surprising doctrine that all variation is Mendelian segregation. I hope he will forgive the bluntness of the expression, but he trifles with established terms. Southsea, November 17.

G. Archdall Reid.

\section{The Winding of Rivers in Plains.}

Sir Oliver Lodge's letter in Nature of November 7 is itself an illustration of his comment on the way in which misunderstanding of cause may lead to misrepresentation of fact. The statements quoted by him are, as is often the case in text-books, inaccurate in so far as they are incomplete, but, nevertheless, in closer accordance with the No. I 986 , vOL. 77$]$ facts of nature, viewed from the geological point of view, than he supposes.

We are not dependent on the calculations of mathematicians for our knowledge of the behaviour of rivers; at one time I had a goodly collection of notes of observations made and published by others, but having unfortunately lost this, I shall write only of what I have seen myself, having had many opportunities of observing the behaviour of rivers which are subject to large variations of flow. In the dry season, when the water is low and the stream flows quietly in a channel of more than sufficient size to carry the discharge, I have noticed that the current is often perceptibly more rapid over the shallow water on the inner side of the bend than in the deep channel on the outer. The line of maximum velocity of flow would, consequently, lie nearer the inner than the outer side of the bend, and be less sinuous than the general course of the river, in accordance with the investigation quoted by Sir Oliver Lodge; but at these times the geological activity of the stream is so small as to be almost negligible. When, on the other hand, the same stream is in flood, and a day's work is more than that of a decade or a century of the placid flow, another state of things prevails; then the current sweeps rapidly round the outer side of the curve, and on the inner side is comparatively slack water. The line of maximum velocity must, therefore, become more sinuous than the river itself, and not only is this result to be reached by deduction, but in some cases it has been visibly perceptible. Further, the undertow on the outer edge of the curve has not been visibly distinguishable in any case that I have seen; if existing, its effect must have been insignificant in comparison with that of the horizontal movement of the stream, and often it certainly does not exist. At times, and in certain circumstances, sand and even pebbles may be thrown up to the surface of the water near the outer bank of the stream, and where the waters have overflowed the banks pebbles may be found lying on the dry ground after the flood has passed away; these facts show that there must, in some cases at least, be an upward, not a downward, current along the bed on the outer side of the bend of a stream.

Do not let me be misunderstood. So far as Sir Oliver Lodge is pleading for accuracy in text-books we are all with him, but when he states, as a positive fact, that the line of maximum velocity of current in a river is less sinuous than the river itself, and that the current along the outer bank of a curve is more rapid than along the inner, then I must join jssue with him and maintain that these statements are only sometimes true. This is no question of the accuracy of Prof. James Thomson's calculations, but they evidently cover only that part of the problem which is least important from a geological point of view.

R. D. Oldham.

\section{"Magic Mirror" Effects.}

I HAD occasion recently to coat with collodion a silver surface mirror on patent plate 2 millimetres thick. During the operation the mirror was held with one of the rubber pneumatic holders frequently used by photographers when coating or varnishing plates. As the film of collodion set, a series of interference colours disposed in concentric circles appeared immediately over the region of the suction disc of the holder. I could scarcely bring myself to encourage the idea which at once occurred to me, viz. that the slight suction of the pneumatic holder was actually deforming so thick a plate of glass and producing an appreciable concavity in its vicinity.

But this seems really to have been the case. For when the beam of light from a lantern (placed with its back to the screen) was reflected back on to the screen by the mirror held with the pneumatic holder, there appeared in the rectangular patch of light determined by the size and shape of the mirror a much brighter internal circular patch which changed its position conformably with any alteration of the position of the pneumatic holder.

I have never seen any reference made to deformations produced in this way; yet such deformations might be found to have a practical significance in critical coating operations where absolute uniformity in the thickness of the coating is desired. Douglas Carnegie. 